\title{
Midazolam-induced Amnesia Reduces Memory for Details and Affects the ERP Correlates of Recollection and Familiarity
}

\author{
Erika Nyhus $^{1,2}$ and Tim Curran ${ }^{2}$
}

\begin{abstract}
Dual process models suggest that recognition memory is supported by familiarity and recollection processes. Previous research administering amnesic drugs and measuring ERPs during recognition memory have provided evidence for separable neural correlates of familiarity and recollection. This study examined the effect of midazolam-induced amnesia on memory for details and the proposed ERP correlates of recognition. Midazolam or saline was administered while subjects studied oriented pictures of common objects. ERPs were recorded during a recognition test 1 day later. Subjects' discrimination of old and new
\end{abstract}

\section{INTRODUCTION}

According to dual process models of recognition, memory is supported by two separate processes (reviewed in Yonelinas, 2002). Whereas familiarity is more general and allows only for recognition of an item without recall of specific information, recollection allows for direct recall of information about items or episodes.

Midazolam, a benzodiazapine commonly used in medical procedures to produce temporary amnesia, has been used to study the processes of recognition memory. Midazolam acts as a neural inhibitor by enhancing the action of gamma aminobutyric acid (GABA). Midazolam increases the binding of GABA to $\mathrm{GABA}_{\mathrm{A}}$ receptors, which are densely expressed in the hippocampus (Kobayashi, Fujito, Matsuyama, \& Aoki, 2004, 2005). Midazolam is ideal for studying memory as it causes a dense (temporary) anterograde amnesia while maintaining higher-level functions such as attention, perception, and semantic memory (Hirshman, Passannante, \& Arndt, 2001).

Midazolam has been used to study the processes of recognition memory (Curran, DeBuse, Woroch, \& Hirshman, 2006; Reder et al., 2006; Hirshman, Fisher, Henthorn, Arndt, \& Passannante, 2002). Three studies suggest that midazolam affects recollection more than familiarity (Curran, DeBuse, et al., 2006; Reder et al., 2006; Hirshman et al., 2002). Hirshman et al. (2002) used the remember/know procedure with low-frequency and high-frequency words and

${ }^{1}$ Brown University, ${ }^{2}$ University of Colorado at Boulder pictures as well as orientation discrimination was worse when they were given midazolam instead of saline. As predicted, the parietal old/new effect was decreased with the administration of midazolam. However, weaker effects on FN400 old/ new effects were also observed. These results provide converging pharmacological and electrophysiological evidence that midazolam primarily affects recollection as indexed by parietal ERP old/new effects and memory for orientation, while also exerting some weaker effects on familiarity as indexed by FN400 old/new effects.

found that subjects made more remember responses following saline than midazolam, and midazoalm decreased the hit rates for low-frequency words while having no effect on false alarm (FA) rates. According to the dual process account of remember/know and word frequency effects (Reder et al., 2000), these results suggest that midaozolam primarily affects recollection. Reder et al. (2006) found that midazolam impaired recognition memory more for words than photographs and more for photographs than abstract pictures. They suggested that this pattern indicates an effect of recollection, rather than familiarity, because recollection is less prevalent for less familiar items that are harder to bind to the experimental context.

ERPs have also been used to study the neural correlates of recognition memory. The FN400 (300-500 msec over frontal regions) and the parietal old/new effect (500800 msec over parietal regions) recorded during recognition tests are more positive for correctly classified old items than new items (Paller, Voss, \& Boehm, 2007; Rugg \& Curran, 2007; Friedman, 2005; Curran \& Friedman, 2004; Schloerscheidt \& Rugg, 2004; Curran \& Cleary, 2003; Curran \& Dien, 2003; Curran, Tanaka, \& Weiskopf, 2002; Curran, 1999, 2000; Friedman \& Johnson, 2000; Mecklinger, 2000; Rugg, Allan, \& Birch, 2000; Rugg et al., 1998; Wilding \& Rugg, 1996). The FN400 is thought to index familiarity, as it is able to separate old from new items, but does not vary with the recollection of specific information from the study episode (Curran \& Cleary, 2003; Curran, 2000; reviewed in Curran, Tepe, \& Piatt, 2006; reviewed in Rugg \& Curran, 2007). The parietal old/new effect is thought to index 
recollection, because it not only separates old from new items but does vary with the recollection of specific information from the study episode (Curran \& Cleary, 2003; Curran, 2000; reviewed in Curran, Tepe, et al., 2006; reviewed in Rugg \& Curran, 2007; Senkfor \& Van Petten, 1998; Wilding \& Rugg, 1996).

Curran, DeBuse, et al. (2006) combined midazolam and ERPs to test the effects of midazolam on the FN400 and the parietal old/new effects. Under midazolam or saline, subjects studied words and were later tested on their recognition for these words while EEG was recorded. The FN400 old/new effect was similar following midazolam and saline, but the parietal old/new effect was smaller following midazolam than saline. In addition, following saline subject's accuracy correlated with parietal effects, but following midazolam subject's accuracy correlated with the FN400. Assuming that the FN400 indexes familiarity and the parietal/old new effect indexes recollection, these results also suggest that midaozolam primarily affects recollection.

Therefore, previous studies have shown that midazolam affects recollection (Reder et al., 2006; Hirshman et al., 2002) and the parietal old/new effect (Curran, DeBuse, et al., 2006). But no study has manipulated factors known to affect recollection and measured the parietal old/new effect concurrently. The purpose of this study was to examine the effect of midazolam-induced amnesia on recollection of specific information from the study episode and the parietal old/new effect. Combining midazolam with ERPs allows us to capitalize on the strengths of each approach. Whereas midazolam provides insight into the processes of recognition memory under normal conditions and with temporary amnesia (Polster, McCarthy, O’Sullivan, Gray, \& Park, 1993), ERPs provide insight into the neural correlates of recognition memory (reviewed in Rugg \& Curran, 2007; Curran, Tepe, et al., 2006). By combining the two approaches, we can gain insight into the neural processes affected by amnesia.

\section{METHODS}

\section{Subjects}

Twenty-seven people participated in the experiment for payment. All subjects gave informed consent. Data from three subjects were discarded because of failure to complete all experimental sessions $(n=1)$, low accuracy $(n=1)$, and experimenter error $(n=1)$. Of the 24 subjects analyzed, there were 15 male and 9 female subjects ranging from 18 to 30 years old. All subjects were right-handed, native English speakers and weighed <83 kg (183 lbs, so as not to exceed the maximum midazolam dosage). Subjects participated in four sessions: (1) a study session under midazolam or saline; (2) a test session the next day; (3) after 7-10 days, a study session under saline or midazolam; and (4) a test session the next day. Drug administration was double-blinded with drug/saline order counterbalanced across subjects. Before each study session, a urine sample was collected to test for toxicology and pregnancy, and a breathalyzer was used to test for alcohol intoxication. The toxicology screen followed a "Drugs of Abuse" profile to screen for 9-tetrahydrocannabinol, opiates, amphetamines, cocaine, phencyclidine, barbiturates, benzodiazepines, and 3,4-methylenedioxymethamphetamine. All procedures were approved by the human research committee of the University of Colorado, in accord with federal guidelines for protection of human subjects.

\section{Stimuli}

Stimuli consisted of 804 pictures of easily nameable objects. Thirty additional pictures were used for practice. All pictures were presented on an LCD computer monitor on a black background. During study lists, pictures were $7.82 \mathrm{~cm}$ wide by $8.15 \mathrm{~cm}$ high, with uncontrolled viewing distance. During test lists, pictures were $7.9 \times 8.4 \mathrm{~cm}$, with viewing distance restricted to $100 \mathrm{~cm}$.

\section{Design}

Drug condition (midazolam, saline) and memory status (same orientation, opposite orientation, new) were manipulated within subjects. Assignment of drug condition to each study session was counterbalanced across subjects. Pictures were randomly assigned to conditions for each subject separately. In each test session, subjects were presented with studied pictures in the same orientation, studied pictures in the opposite orientation, and new pictures. Test key assignments were counterbalanced across subjects.

\section{Procedure}

Each 2-hr study session was run at the Clinical and Translational Research Center at the University of Colorado at Boulder. Qualified medical staff and cardiopulmonary resuscitation equipment were available throughout the session. After completing a consent form and brief medical screening, subjects performed a practice study and test block. Practice blocks consisted of 20 study pictures, presented twice, and 30 test pictures (10 same orientation, 10 different orientation, and 10 new). Subjects were provided feedback on their test accuracy during the practice.

Following the practice study and test block, an intravenous catheter was inserted, and subjects were given an injection of either $0.03 \mathrm{mg} / \mathrm{kg}$ of body weight of midazolam diluted to a total volume of $10 \mathrm{ml}$ or $10 \mathrm{ml}$ of saline. The injection was given over 2 min, with a maximum dose of $2.5 \mathrm{mg}$ (thus, maximum weight of subjects was $83 \mathrm{~kg}$ ). The plasma half-life of midazolam is 1-4 hrs (Feldman, Meyer, \& Quenzer, 1997). Following drug administration subjects completed eight study blocks.

In each study session, there were eight blocks in which subjects viewed 268 pictures in total. The beginning and 
end of each block contained two pictures that were used as practice test pictures. Subjects studied the pictures and, using their index finger of both hands, indicated whether they thought the picture was oriented to the left (left) or to the right (right). After all the pictures were shown once, they were repeated in a different order, and subjects were provided with auditory feedback to indicate whether their response was the same (ding) or different (beep) from their response to the first presentation of the picture. Pictures were presented for $2000 \mathrm{msec}$ with a 500 msec intertrial interval. If the subject failed to make a response within $2000 \mathrm{msec}$, the computer dinged until a response was made (see Figure 1, left). Subjects were allowed to rest following each study block. To determine the efficacy of midazolam, after completion of the study task, subjects studied a list of 10 names or 10 city names that they were asked to recall at the beginning of the test phase. Subjects also performed a verb generation task that was previously reported (Snyder et al., 2010).

One day later subjects were tested on their memory for studied pictures. Each 2-hr test session began with a practice test block. The practice block consisted of 24 test pictures (eight same orientation, eight opposite orientation, and eight new) after which each subject completed three test blocks.

The test phase contained the 268 studied pictures intermixed with 134 new pictures. Previously studied pictures were divided such that half of the pictures appeared in the same orientation as at study and half appeared in the opposite orientation as at study. Subjects were given a break after every $1.5 \mathrm{~min}$. Test trials included a variable duration (500-1500 msec) fixation (+) followed by a test picture. Each test picture was presented for $3000 \mathrm{msec}$. Upon appearance of the test picture, subjects were able to respond. Using their index and middle finger of one hand and their index finger of the other hand, subjects pressed a key for old same, old different, or new (see Figure 1, right).

\section{EEG/ERP Recording and Analysis}

During the test phase of the experiment scalp voltages were collected with a 256-channel HydroCel Geodesic Sensor Net connected to an AC-coupled, 256-channel, high-input impedance amplifier (200 M $\Omega$, Net Amps, Electrical Geodesics, Inc., Eugene, OR). Amplified analog voltages (0.1-100 Hz bandpass) were digitized at $250 \mathrm{~Hz}$. Individual sensors were adjusted until impedances were less than $50 \mathrm{k} \Omega$.

The EEG was baseline-corrected to a 200-msec prestimulus recording interval and digitally low-pass filtered at $40 \mathrm{~Hz}$. Individual channels were replaced on a trial-bytrial basis with a spherical spline algorithm (Srinivasan, Nunez, Tucker, Silberstein, \& Cadusch, 1996). Trials were discarded from analysis if more than $20 \%$ of the channels were bad (average amplitude over $100 \mu \mathrm{V}$ or over $50 \mu \mathrm{V}$ between adjacent samples) or subjects failed to respond within $4000 \mathrm{msec}$ to the studied picture. EEG was measured with respect to a vertex reference $(\mathrm{Cz})$ but was rereferenced to an average mastoid reference.

For ERP analysis, mean amplitudes were compared between conditions in frontal (FN400) and parietal channels (parietal old/new effect). To consider the broader topography of the results, differences between old correct orientation and new pictures and old incorrect orientation and new pictures were scaled using a range normalization method (McCarthy \& Wood, 1985). Using this method, different scalp topographies can indicate different neuronal
Figure 1. Experimental paradigm and the data categories resulting from it.

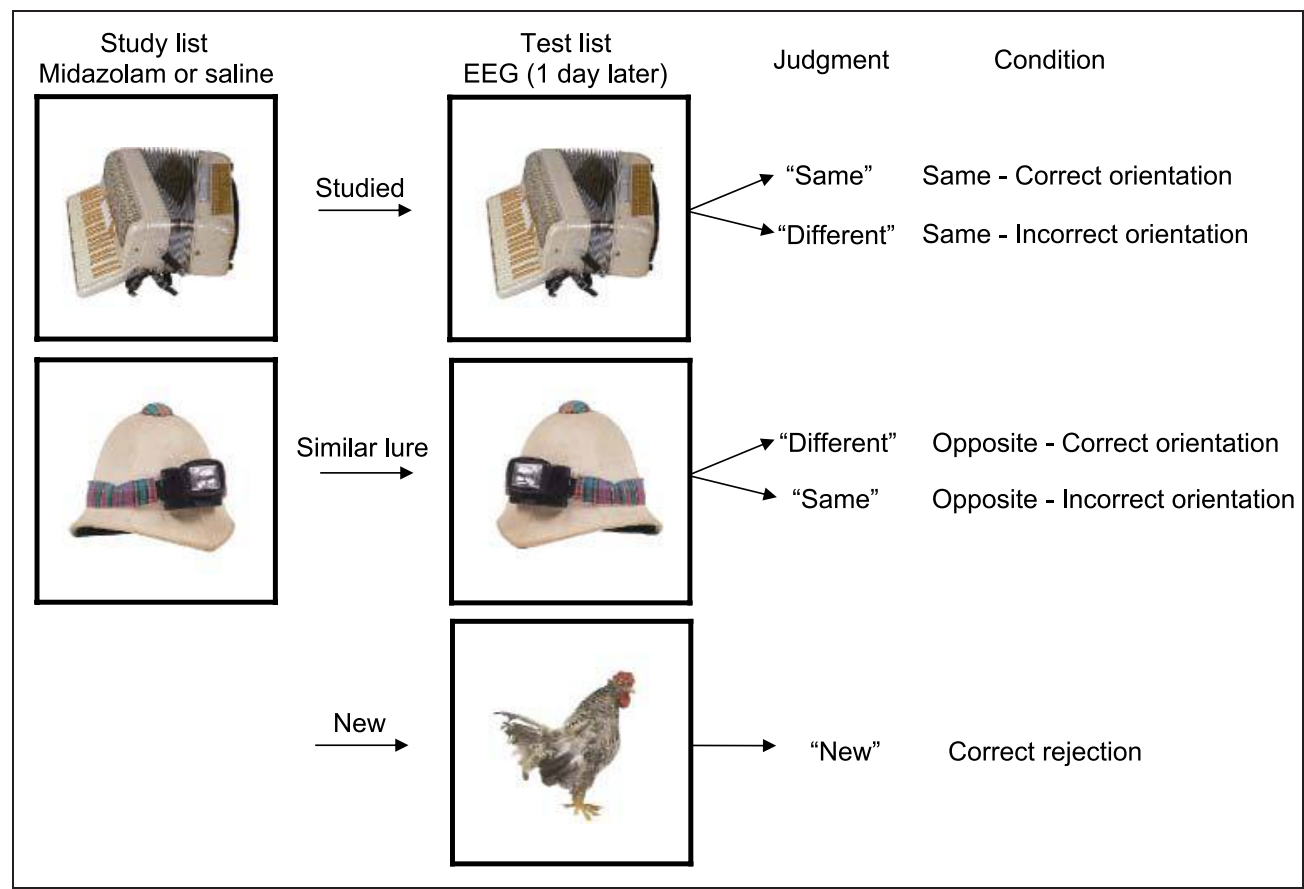


sources or the same sources with different distributions of source strengths.

\section{RESULTS}

\section{Behavioral Results}

Studied pictures were eliminated from all analyses if subjects failed to respond with a left/right judgment within $4000 \mathrm{msec}$ during either presentation at study. There were more words removed following midazolam $(M=15.04)$ than saline $(M=.67 ; F(1,23)=64.66, M S E=37.25$, $p<.01)$. Recognition memory analyses were performed on item and orientation discrimination $\left(d^{\prime}\right)$ and response bias (c). Item $d^{\prime}$ and $c$ was measured independently from orientation $d^{\prime}$ and $c$, as previous studies have done for source memory (Slotnick \& Dodson, 2005; Murnane \& Bayen, 1996). For same orientation and opposite orientation, an item hit was anytime a subject responded "Old Same" or "Old Different" to an old item, regardless of whether they classified the orientation correctly, and an item FA was anytime a subject responded "Old Same" or "Old Different" to a new item. An orientation hit was anytime a subject responded "Old Same" for an item studied in the same orientation as at study, and an orientation FA was anytime a subject responded "Old Same" for an item studied in the opposite orientation as at study. Item $d^{\prime}$ and $c$ were calculated by comparing old to new items for both same orientation and opposite orientation pictures (hit same orientation vs. FA and hit different orientation vs. FA), whereas orientation $d^{\prime}$ was calculated for item hits only (hit same correct orientation vs. hit different incorrect orientation).

Item $d^{\prime}$ and $c$ were compared between midazolam and saline conditions with a Drug (midazolam, saline) $\times$ Orientation (same, different) repeated measures ANOVA (see Table 1). Item $d^{\prime}$ was higher following saline than midazolam $(F(1,23)=55.92$, MSE $=.40, p<.01)$. Neither the orientation effect nor its interaction with drug approached significance for item $d^{\prime}$. No main effects or interactions were significant for response bias $(c)$.

Table 1. Item Behavioral Data

\begin{tabular}{llcc}
\hline & \multicolumn{1}{c}{ Condition } & Midazolam & Saline \\
\hline Hit & Same orientation & $0.59(0.04)$ & $0.74(0.03)$ \\
& Opposite orientation & $0.56(0.04)$ & $0.74(0.03)$ \\
FA & & $0.23(0.04)$ & $0.11(0.02)$ \\
Item $d^{\prime}$ & Same orientation & $1.16(0.18)$ & $2.08(0.14)$ \\
& Opposite orientation & $1.08(0.17)$ & $2.10(0.16)$ \\
Item $c$ & Same orientation & $0.33(0.09)$ & $0.34(0.06)$ \\
& Opposite orientation & $0.37(0.10)$ & $0.33(0.06)$ \\
\hline
\end{tabular}

Means with standard errors in parentheses.
Table 2. Orientation Behavioral Data

\begin{tabular}{llcc}
\hline & & Midzolam & Saline \\
\hline Hit & $\begin{array}{c}\text { Same orientation } \\
\text { correct }\end{array}$ & $0.66(0.03)$ & $0.81(0.02)$ \\
FA & $\begin{array}{l}\text { Opposite orientation } \\
\text { incorrect }\end{array}$ & $0.57(0.03)$ & $0.41(0.02)$ \\
Orientation $d^{\prime}$ & & $0.28(0.11)$ & $1.20(0.10)$ \\
Orientation $c$ & & $-0.36(0.08)$ & $-0.36(0.05)$ \\
\hline
\end{tabular}

Means with standard errors in parentheses.

Orientation $d^{\prime}$ and $c$ were compared between midazolam and saline conditions with a two saline/midazolam repeated measures ANOVA (see Table 2). Although orientation $d^{\prime}$ was significantly above chance following midazolam $(F(1$, $23)=6.13, M S E=.15, p=.02$ ), orientation $d^{\prime}$ was higher following saline than midazolam $(F(1,23)=81.02, M S E=$ $.13, p<.01)$. Orientation response bias (c) did not differ following midazolam and saline.

RTs were analyzed with a Drug $\times$ Memory Status (correct orientation to old pictures, incorrect orientation to old pictures, and correct rejection of new pictures) repeated measures ANOVA (see Table 3). These conditions were selected to mirror the ERP analysis. RTs were faster following saline than midazolam $(F(1,23)=12.20, M S E=39,873, p<.01)$. There was a main effect of Memory status such that RTs were faster for new than old correct orientation and incorrect orientation pictures $(F(2,46)=121.91, M S E=23,823$, $p<.01)$. The difference between new and old correct orientation pictures was significant $(F(1,23)=143.92$, $M S E=3,428,456, p<.01)$ as well as the difference between new and old incorrect orientation pictures $(F(1,23)=$ $214.75, M S E=5,115,858, p<.01)$ and old correct orientation and incorrect orientation pictures $(F(1,23)=7.06$, $M S E=168,278, p=.02)$. Drug did not interact with memory status $(F(2,46)=2.87, M S E=15,859)$.

Midazolam also reduced free recall performance for the names presented after the main experiment study list, confirming that the drug was effective through the entire study list for the main experiment. Analysis of free recall of the names studied after the picture study list was performed on the number of correctly recalled names and incorrectly recalled names. There were more correctly recalled names following saline $(M$ correctly recalled $=3.08$ ) than midazolam $(M$ correctly recalled $=.75),(F(1,23)=$ $38.86, M S E=1.68, p<.01)$. The number of incorrectly

Table 3. Reaction Time Data

\begin{tabular}{llcc}
\hline & \multicolumn{1}{c}{ Condition } & Midazolam & Saline \\
\hline RT & Correct orientation & $1672(53)$ & $1492(46)$ \\
& Incorrect orientation & $1695(54)$ & $1637(54)$ \\
& New & $1260(60)$ & $1149(47)$ \\
\hline
\end{tabular}

Means with standard errors in parentheses. 
recalled names (intrusion errors) did not differ following midazolam ( $M$ incorrectly recalled $=1.63$ ) and saline $(M$ incorrectly recalled $=1.17), F(1,23)=1.57, M S E=1.61$.

\section{ERP Results}

Spatio-temporal ROIs for the 256-channel Geodesic Sensor Net (GSN 200 v. 2.1; Tucker, 1993) were chosen to correspond to ROIs for the 128-channel Geodesic Sensor Net (GSN 200 v. 2.1; Tucker, 1993) used in previous research for both the FN400 and parietal old/new effects (Curran, DeBuse, et al., 2006). For the FN400 old/new effects, ROIs were the left and right anterior, superior channel groups (LAS and RAS shown in Figure 2); mean amplitude from 300 to 500 msec was computed by averaging the channels within each region for each condition/subject. For the parietal old/new effects, ROIs were the left and right posterior, superior channel groups (LPS and RPS shown in Figure 2); mean amplitude from 500 to $800 \mathrm{msec}$ was computed by averaging the channels within each region for each condition/subject. Mean FN400 and parietal ERP amplitude values are shown in Table 4 . Average waveforms are shown in Figure 3, and topographic plots of the ERP old/new differences are shown in Figures 4 and 5. Mean amplitudes were analyzed with a Drug $\times$ Memory Status $\times$ Hemisphere (left, right) repeated measures ANOVA. ANOVA results that were not reported were not significant.

\section{FN400 Effects}

There was a main effect of Memory status such that amplitudes were more positive for old correct orientation and incorrect orientation than new pictures $(F(2,46)=$ 6.00, $M S E=2.19, p<.01)$. The difference between old

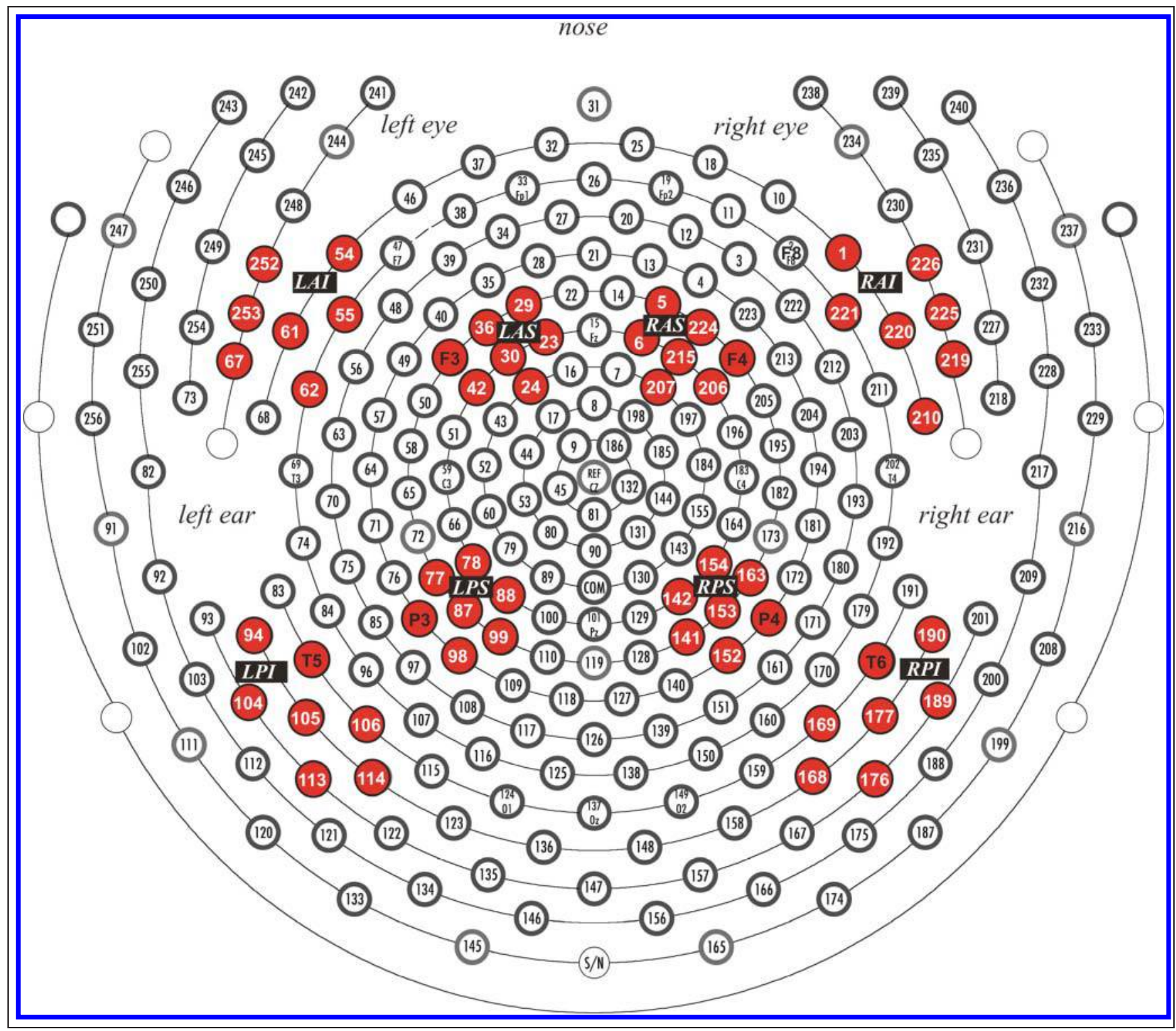

Figure 2. Geodesic sensor net layout. Electrode sites are numbered along with selected 10-10 positions. Black clusters are ROIs included in analyses. $\mathrm{L}=$ left, $\mathrm{R}=$ right, $\mathrm{A}=$ anterior, $\mathrm{P}=$ posterior, $\mathrm{I}=$ inferior, and $\mathrm{S}=$ superior. 
Table 4. ERP Data

\begin{tabular}{lcc}
\hline Condition & Midzolam & Saline \\
\hline FN400 & $-7.08(0.72)$ & $-6.68(0.76)$ \\
Correct orientation & $-7.09(0.77)$ & $-7.15(0.76)$ \\
Incorrect orientation & $-7.77(0.72)$ & $-7.44(0.75)$ \\
New & & \\
Parietal & $0.95(0.37)$ & $2.06(0.27)$ \\
Correct Orientation & $1.10(0.38)$ & $1.36(0.30)$ \\
Incorrect Orientation & $0.74(0.27)$ & $1.28(0.28)$ \\
New &
\end{tabular}

Means with standard errors in parentheses.

correct orientation and new pictures was significant $(F(1$, $23)=11.57, M S E=25.26, p<.01)$ as well as the difference between old incorrect orientation and new pictures $(F(1,23)=5.14, M S E=11.23, p=.04)$. There was no main effect or interactions involving the drug factor, including the Drug $\times$ Memory Status interaction $(F(1,23)=.62$, $M S E=2.45)$. Although there was no interaction between Drug and Memory status $(F(2,46)=.62, M S E=2.45)$, pairwise comparisons investigated potential differences that are visually apparent in Figure 3. Both drug conditions were associated with significant differences between old correct orientation and new pictures (midazolam: $F(1$, $23)=4.69, M S E=11.52, p=.04$; saline: $F(1,23)=$ $5.62, M S E=13.80, p=.03)$, and neither showed significant differences between old correct orientation and incorrect orientation pictures (midazolam: $F(1,23)=.001, M S E=$ .002 ; saline: $F(1,23)=2.19, M S E=5.38)$. However, differences between old incorrect orientation and new pictures were only significant following midazolam $(F(1,23)=4.56$, $M S E=11.18, p=.04$; saline: $F(1,23)=.79, M S E=1.95)$.

\section{Parietal Effects}

There was a main effect of Memory status such that amplitudes were more positive for old correct orientation than incorrect orientation and new pictures $(F(2,46)=$ $4.60, M S E=1.29, p=.02)$. The difference between old correct orientation and new pictures was significant $(F(1$, $23)=9.14, M S E=11.83, p<.01)$. There was a main effect of Hemisphere such that amplitudes were more positive in the right than the left hemisphere $(F(1,23)=6.70, M S E=$ $3.48, p=.02)$. Importantly, drug interacted with Memory status, such that the difference between old correct orientation and incorrect orientation pictures was greater following saline than midazolam $(F(2,46)=4.58, M S E=.97, p=$ $.02)$. Following saline, the difference between old correct orientation and new pictures was significant $(F(1,23)=$ $15.11, M S E=14.66, p<.01)$ as well as the difference between old correct orientation and incorrect orientation pic- tures $(F(1,23)=12.18$, MSE $=11.82, p<.01)$. Following midazolam, there were no differences between old correct orientation and new pictures $(F(1,23)=1.11, M S E=$ $1.07)$, old incorrect orientation and new pictures $(F(1$, $23)=3.09, M S E=2.99$ ), or old correct orientation and incorrect orientation pictures $(F(1,23)=.50, M S E=.48)$.

\section{Range Normalized Difference Scores}

To consider the broader topography of the results, we calculated mean amplitudes for eight electrode groups (see Figure 2). The range normalized difference scores were compared in a Time (300-500 msec/500-800 msec) $\times$ Drug $\times$ Orientation Accuracy (correct orientation, incorrect orientation) $\times$ Superior/Inferior $\times$ Anterior/Posterior $\times$ Hemisphere Repeated Measures ANOVA. To focus on the distinct topography of the FN400 and parietal old/new effects, we only report effects that interacted with time and location.

There was an interaction between Time, Drug, Orientation accuracy, and Anterior/Posterior $(F(1,23)=7.22$, $M S E=.38, p=.01)$. For the FN400, old/new differences were more prominent over anterior locations but smallest when orientation was incorrect following saline. For the parietal effect, old/new differences were more prominent over posterior locations and more positive following saline than midazolam when orientation was correct. This more anterior distribution from 300 to $500 \mathrm{msec}$ and more posterior distribution from 500 to $800 \mathrm{msec}$ is consistent with our a priori selected frontal ROIs for the FN400 effect and posterior ROIs for the parietal old/new effect.

\section{DISCUSSION}

The purpose of the present experiment was to determine how midazolam affects memory for details and ERP old/ new effects. Item and orientation discrimination was greater following saline than midazolam. The parietal $\mathrm{old} /$ new effect differed between orientation correct and orientation incorrect pictures following saline but not midazolam. When memory for orientation was correct, the FN400 differentiated old and new pictures following both saline and midazolam. However, when memory for orientation was incorrect, the FN400 differentiated old and new pictures following midazolam but not following saline.

The larger effect of midazolam on the parietal old/new effect is consistent with previous studies showing that midazolam primarily affects recollection. Hirshman et al. (2002) found that subjects made more remember responses following saline than midazolam, and midazolam decreased the hit rates for low-frequency words while having no effect on FA rates suggesting that midaozolam primarily affects recollection. Reder et al. (2006) found that midazolam had larger effects on memory for stimuli 
that were more likely to be recollected. Curran, DeBuse, et al. (2006) found that the FN400 old/new effect was similar following midazolam and saline, but the parietal old/new effect was smaller following midazolam than saline. But these studies were limited by examining only behavior (Reder et al., 2006; Hirshman et al., 2002) and examining ERP effects in a standard recognition design that does not specifically target recollection (Curran, DeBuse, et al., 2006). Extending these studies, the current design specifically manipulated factors known to affect recollection and found that midazolam affected recollection of specific information from the study episode and the parietal old/new effect.
Unexpectedly, FN400 old/new differences were observed regardless of orientation accuracy following midazolam but only when memory of orientation was correct following saline. These results should be interpreted with caution, because they arose from pairwise comparisons that were not accompanied by a significant drug by memory status interaction, but Veselis et al. (2009) also showed decreased FN400 old/new effects following midazolam and Curran and Cleary (2003) observed similar trends in an experiment on memory for picture orientation, which compared separate groups of subjects with good versus poor memory for orientation. Although there was no significant interaction between group
Figure 3. Average ERP waveforms for correct orientation, incorrect orientation, and new for the FN400 (LAS and RAS regions, 300-500 msec) and parietal old/new effect (LPS and RPS regions, 500-800 msec) for the midazolam condition (A) and the saline condition (B).

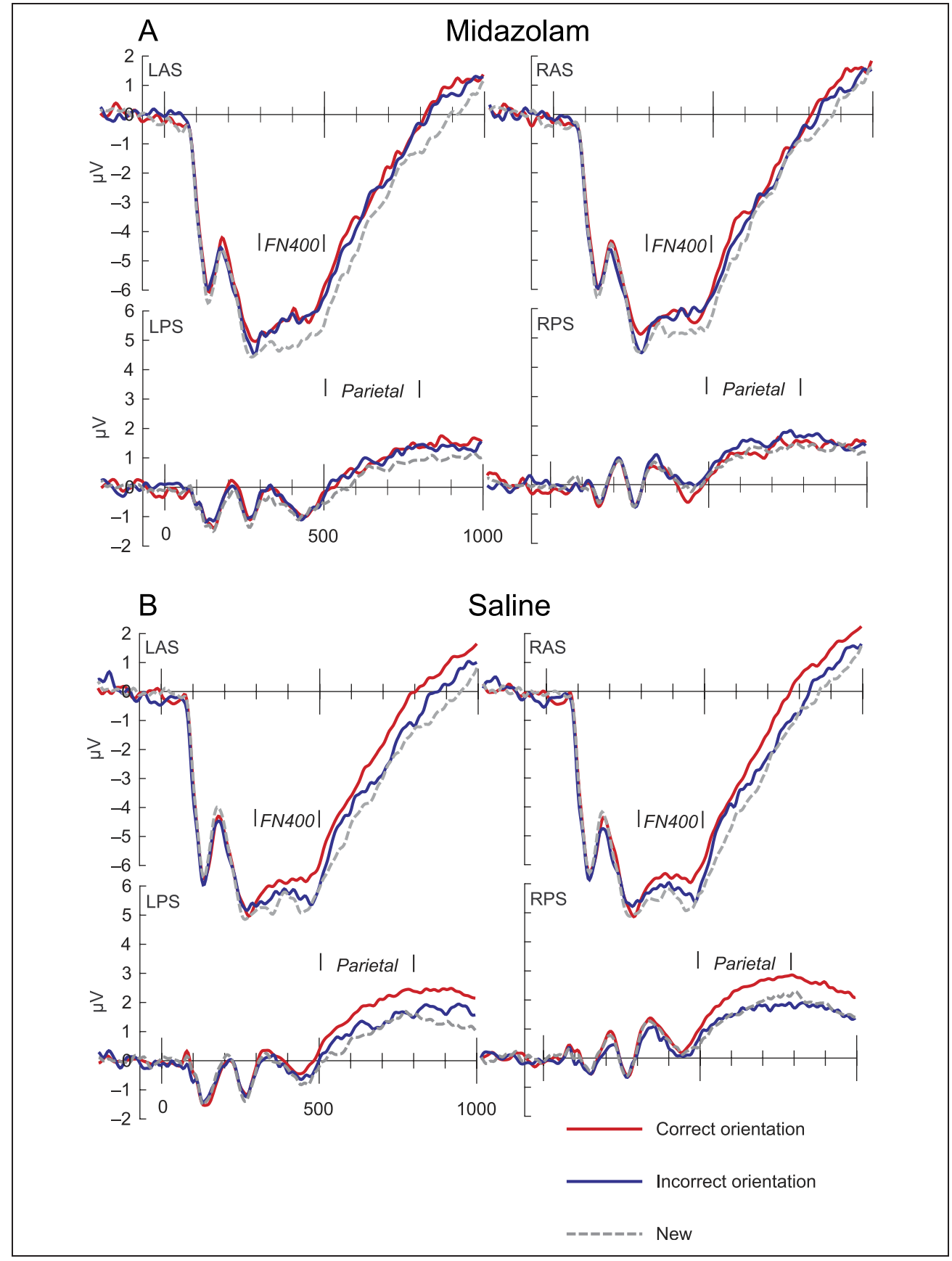


Figure 4. Topographic plots of correct orientation/new differences for midazolam (top) and saline (bottom) from 300 to $800 \mathrm{msec}$ in 100 -msec intervals.

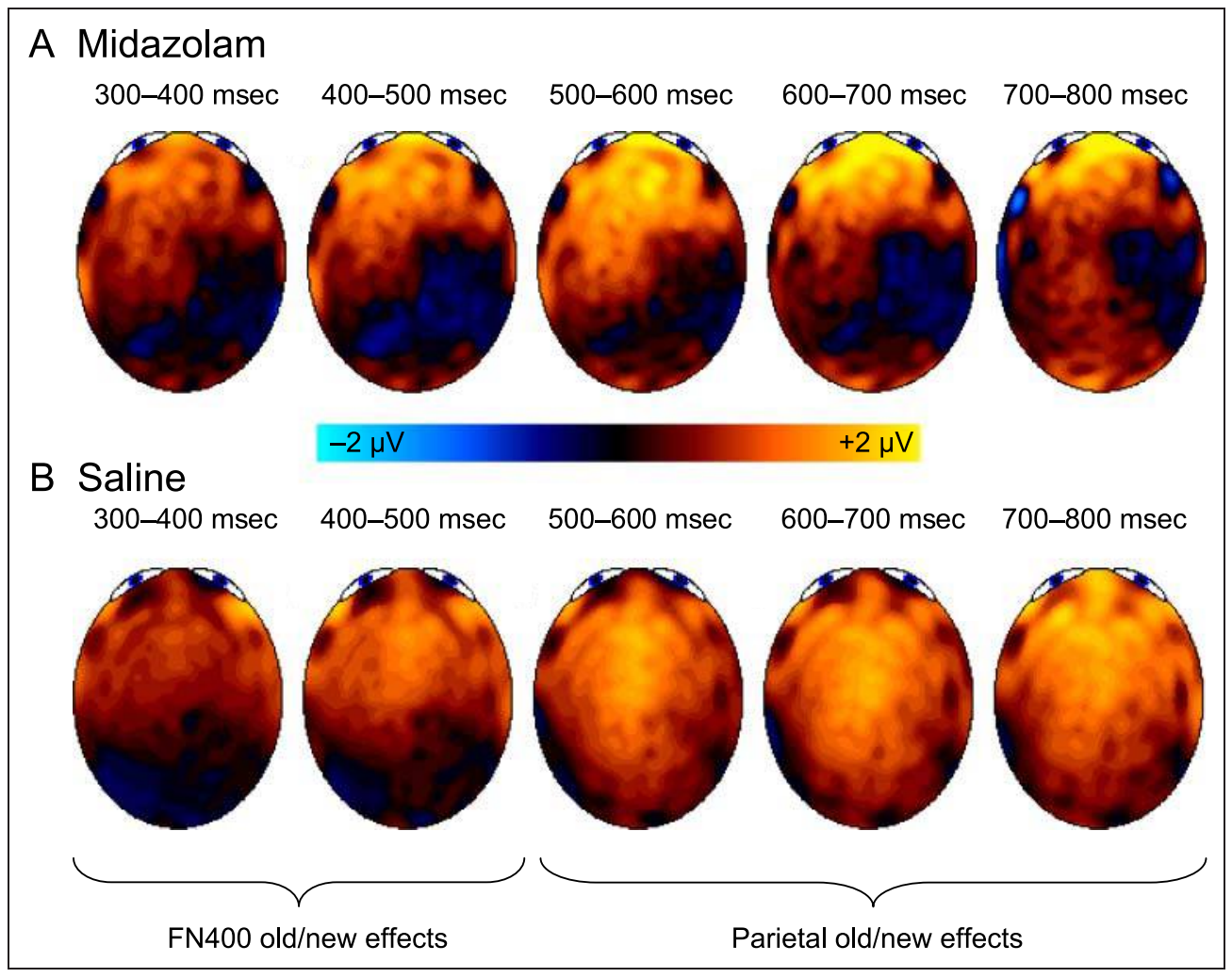

and orientation accuracy on FN400 amplitude, there were trends toward greater orientation accuracy effects in the good memory group (like the present saline condition) than in the poor memory group (like the present midazolam condition).
The effect of midazolam on familiarity in this study sheds light on the effects of midazolam at encoding on later recognition processes. Reder et al. (2006) suggest that midazolam specifically affects recollection because it selectively inhibits binding of items with their context.
Figure 5. Topographic plots of incorrect orientation/new differences for midazolam (top) and saline (bottom) from 300 to $800 \mathrm{msec}$ in $100-$ msec intervals.

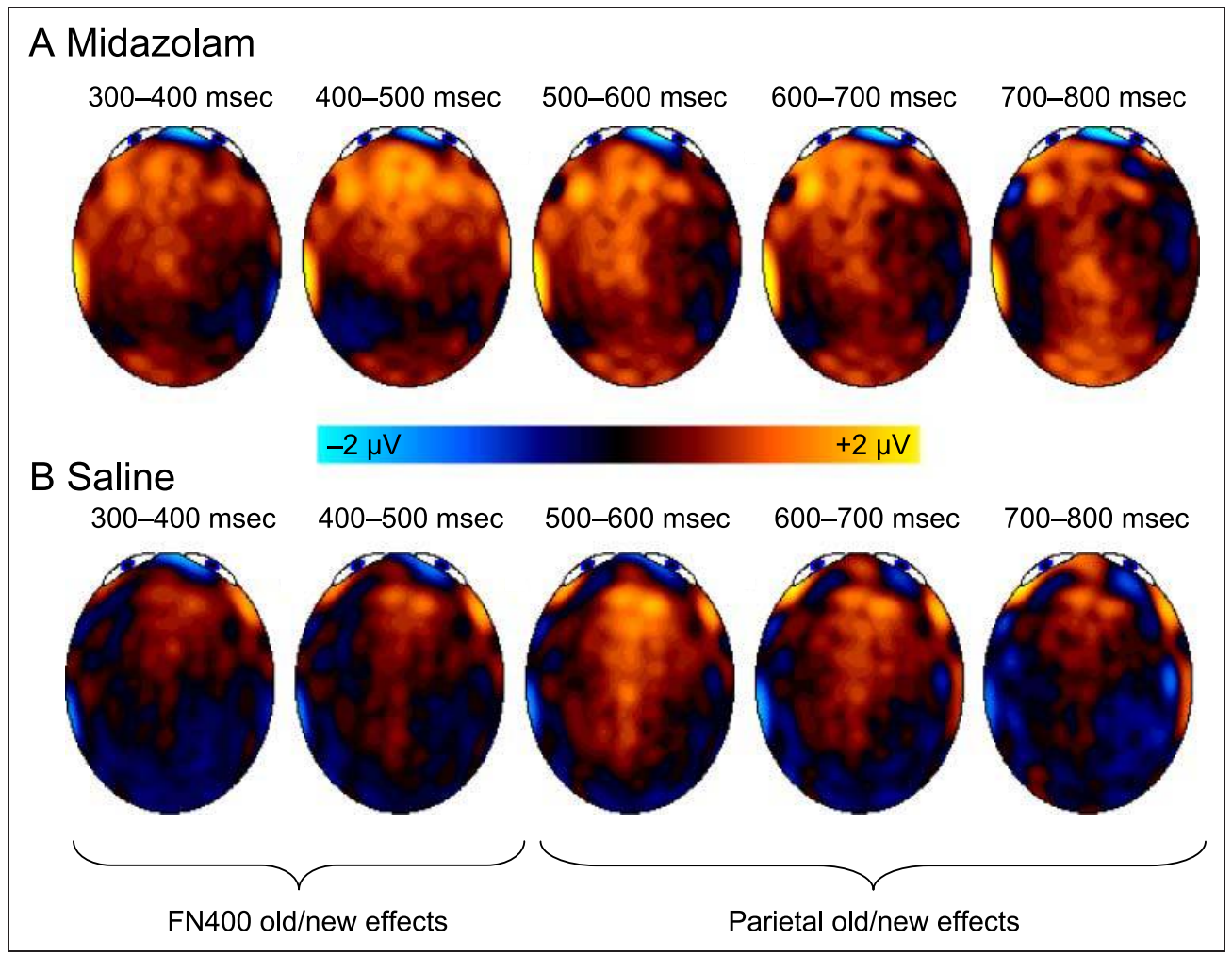


Reder et al. (2006) showed that midazolam had the largest effect on memory for words, an intermediate effect on memory for pictures of common objects, and no effect on memory for abstract pictures. Midazolam was thought to specifically affect recollection for words because words are more readily bound to their context. However, Park, Quinlan, Thornton, and Reder (2004) found evidence suggesting that midazolam does not selectively affect recollection. In an implicit visual search task, following midazolam, subjects did not show facilitation in search times for repeated configurations. These results suggest that midozolam decreases binding of representations during encoding regardless of the type of memory processes engaged at retrieval.

The present results are the first to show that midazolam, given at encoding, can affect familiarity-based discrimination of picture orientation, which can be conceptualized as involving the binding of objects with their orientation that later affect familiarity processes at retrieval. The FN400 results are consistent with studies showing that perceptual match can affect familiarity (Nyhus \& Curran, 2009; Ecker, Zimmer, \& Groh-Bordin, 2007; Groh-Bordin, Zimmer, \& Ecker, 2006). Perceptual match effects refer to an increase in familiarity observed when test stimuli are perceptually identical to studied stimuli compared with cases where perceptual attributes are changed between study and test. Ecker et al. (2007) and Groh-Bordin et al. (2006) have shown perceptual match effects by manipulating picture color. Zimmer and Ecker (2010) describe these and related results by postulating differences in processing between intrinsic information (within-item features of an object such as color) and extrinsic information (context). According to their theory, intrinsic information is bound in object tokens that are retrieved and therefore affect both familiarity and recollection processes. These results are in agreement with recent models and physiological evidence suggesting that medial-temporal lobe structures (perirhinal cortex) support the biding of feature conjunctions contributing to familiarity whereas the hippocampus supports the binding of items with their spatio-temporal contexts contributing to recollection (Cowell, Bussey, \& Saksida, 2010; Montaldi \& Mayes, 2010; Norman, 2010). The results of this study are in general agreement with Ecker et al.'s theory because orientation changes are intrinsic (Ecker et al., 2007). Importantly, the present results extend their findings (Ecker et al., 2007; Groh-Bordin et al., 2006) to pictures with an intrinsic orientation feature and by showing that intrinsic perceptual match effects are diminished following midazolam. These results also relate to studies on associative recognition. Recent studies have examined the processes involved in recognizing the association of two items. Although it has been assumed that associative recognition depends on recollection, some studies have shown that familiarity can support associative recognition when individual item representations can be unitized into a single representation (Quamme, Yonelinas, \& Norman, 2007; Speer \& Curran, 2007; Caldwell \& Masson, 2001;
Yonelinas, Kroll, Dobbins, \& Soltani, 1999). The present results extend these findings by suggesting that, in addition to unitization of items, unitization of items and intrinsic features can lead to familiarity supporting associative recognition following saline but not following midazolam.

Midazolam has been shown behaviorally to selectively affect encoding, but it is unclear how midazolam influences encoding-related activity (Polster et al., 1993). A previous fMRI study showed both state and item effects during encoding related to successful retrieval (Otten, Henson, \& Rugg, 2002). Specifically, sustained activity in parietal and $\mathrm{pFC}$ correlated with subsequent recall. Although in this study encoding-related EEG was not recorded, retrievalrelated ERPs could have resulted from differential encoding states under midazolam and saline, leading to poorer memory following midazolam and decreased FN400 and parietal old/new effects during retrieval. The aforementioned binding processes would be more consistent with item effects, but pertinent state effects might include a sustained focus on the need to attend to orientation during encoding that could have been dampened by midazolam.

The foregoing discussion focused on effects of midazolam during encoding, but a consideration of retrieval processes may also be relevant. Ecker and Zimmer (2009) found that the FN400 effects could be modulated by how focused subjects were on perceptual details during retrieval. Under the specific retrieval orientation condition, subjects were told to accept only pictures that were the same from study to test, whereas under the general retrieval orientation condition, subjects were told to accept both pictures that were the same from study to test and new exemplars of studied objects. FN400 differences between same and different exemplars was greater for the specific retrieval orientation condition than the general retrieval orientation condition. In this study with picture orientation, the midazolam FN400 results are similar to Ecker and Zimmer's (2009) general orientation results and the saline FN400 results are similar to Ecker and Zimmer's (2009) specific orientation results. Therefore, it is possible that subjects used a specific retrieval orientation following saline but midazolam decreased subject's memory for details and pushed them toward a more general retrieval orientation.

The analyses of range normalized difference scores showed distinct topographical patterns for the FN400 and the parietal old/new effect. The poor spatial resolution of EEG is not able to localize familiarity and recollection processes, but direct comparison of fMRI and ERP old/new effects indicate that the ERP parietal old/new effect reflects recollection-sensitive areas of the lateral parietal cortex (Vilberg \& Rugg, 2007, 2009; Vilberg, Moosavi, \& Rugg, 2006; Woodruff, Hayama, \& Rugg, 2006; Yonelinas, Otten, Shaw, \& Rugg, 2005). Although the neural source of the ERP parietal old/new effect is likely in lateral parietal cortex, there is some evidence that it is dependent on the functioning of the hippocampus. In a patient with hippocampal damage, the ERP parietal old/new effect was greatly reduced compared with control subjects during recognition 
of studied words (Düzel, Vargha-Khadem, Heinze, \& Mishkin, 2001). Therefore, the ERP parietal old/new effect may be dependent on the functioning of the hippocampus, which is known to be important for recollection. In addition, the selective binding of midazolam is consistent with a hippocampal contribution to recollection effects. Midazolam increases the binding of GABA to $\mathrm{GABA}_{\mathrm{A}}$ receptors. Although $\mathrm{GABA}_{\mathrm{A}}$ receptors are widely expressed throughout the brain, they are prevalent in the hippocampus, where they are thought to cause amnesic effects (Kobayashi et al., 2004, 2005). In addition, the neural source of the ERP FN400 effect is likely in pFC (Rugg \& Curran, 2007). Although midazolam has strong effects on the hippocampus, there is also evidence that prefrontal cortical regions are also affected by midazolam (Hirshman, Fisher, Henthorn, Arndt, \& Passannante, 2003; Reinsel et al., 2000).

Although there is a general agreement that the FN400 and parietal old/new effect represent dissociable neural components (reviewed in Rugg \& Curran, 2007), there is some disagreement about which memory processes these neural components represent. It was assumed that the FN400 indexes familiarity and the parietal old/new effect indexes recollection, but the relationship between these ERP components and processes has been debated.

An alternative hypothesis is that the FN400 indexes a form of implicit memory, conceptual priming (Paller et al., 2007; Voss \& Paller, 2006; Yovel \& Paller, 2004). Conceptual priming is a form of repetition priming in which semantic information is repeated. There may be some overlap between conceptual priming and familiarity (e.g., Yonelinas, 2002), and it is therefore difficult to separate out the contribution of conceptual priming and familiarity to the FN400 component. But the present orientation effects on the FN400 add to previous ERP studies supporting the idea that the FN400 is related to familiarity and not conceptual priming (Yu \& Rugg, 2010; Stenberg, Hellman, Johansson, \& Rosen, 2009) and a previous behavioral study showing that midazolam affects explicit and not implicit conceptual processing (Arndt, Passannante, \& Hirshman, 2004). Therefore, this evidence suggests that the conceptual priming account of the FN400 is too limited. Rather, it is likely that the FN400 represents familiarity, which can include both conceptual and perceptual contributions.

In addition to the debate about the relationship of the FN400 to familiarity, some have argued that the parietal old/new effect represents decisional factors rather than recollection. Finnigan, Humphreys, Dennis, and Geffen (2002) showed that the FN400 was sensitive to the strength of studied items, but the parietal old/new effect was sensitive to the accuracy of responses or decisional factors. They suggested that a single familiarity process is sufficient for recognition for single-item recognition tasks, but they also noted the possibility of an additional recollection process being involved in more complex recognition tasks that require memory for details such as study plurality or source. However, Woodruff et al. (2006) found that the
FN400 differentiates confident from not confident remembered items, but the parietal old/new effect differentiates items recollected with specific details of the study episode and highly confident old responses without recollection of specific details of the study episode. These results indicate that recollection is unique and does not only represent a high-confidence response (see also Curran, 2004). Given other evidence reviewed above suggesting that midazolam affects recollection, this study adds weight to the view that the parietal old/new effect indexes recollection, rather than decisional factors.

\section{Conclusions}

Both midazolam and ERPs have been used to study the processes of recognition memory, but no previous study has manipulated recollection of details and measured ERPs concurrently. Midazolam provides insight into the processes of recognition memory under normal conditions and with temporary amnesia (Polster et al., 1993), and ERPs provide insight into the neural correlates of recognition memory (reviewed in Rugg \& Curran, 2007; Curran, Tepe, et al., 2006). The present results indicate that midazolam primarily affects recollection as indexed by parietal ERP old/new effects and memory for orientation, while also exerting some weaker effects on familiarity as indexed by FN400 old/new effects.

\section{Acknowledgments}

This work was supported by NIH Grant RO1-MH64812 and by NIH/NCRR Colorado CTSI Grant UL1 RR025780. Contents are the authors' sole responsibility and do not necessarily represent official NIH views. We thank the staff of the University of Colorado Boulder Clinical and Translational Research Center for medical assistance; Casey DeBuse and Brent Young for help with experiment programming; Colin Argys, Christopher Bird, Alexander Eichenbaum, Robert Garcia, William Hall, Philip Jensen, Emily Kleinfelder, and Portia Payne for subject testing; and Grit Herzmann for providing Figure 2.

Reprint requests should be sent to Erika Nyhus, Cognitive, Linguistic, and Psychological Sciences, Brown University, 190 Thayer St., Providence, RI 02912-1821, or via e-mail: Erika_Nyhus@ brown.edu.

\section{REFERENCES}

Arndt, J., Passannante, A., \& Hirshman, E. (2004). The effect of midazolam on implicit and explicit memory in category exemplar production and category cued recall. Memory 12, 158-173.

Caldwell, J. I., \& Masson, M. E. (2001). Conscious and unconscious influences of memory for object location. Memory and Cognition, 29, 285-295.

Cowell, R. A., Bussey, T. J., \& Saksida, L. M. (2010). Components of recognition memory: Dissociable cognitive processes or just differences in representational complexity? Hipbocampus, 20, 1245-1262.

Curran, T. (1999). The electrophysiology of incidental and intentional retrieval: ERP old/new effects in lexical decision and recognition memory. Neuropsvchologia. 37, 771-785. 
Curran, T. (2000). Brain potentials of recollection and familiarity. Memory \& Cognition, 28, 923-938.

Curran, T. (2004). Effects of attention and confidence on the hypothesized ERP correlates of recollection and familiarity. Neuropsychologia, 42, 1088-1106.

Curran, T., \& Cleary, A. M. (2003). Using ERPs to dissociate recollection from familiarity in picture recognition. Cognitive Brain Research, 15, 191-205.

Curran, T., DeBuse, C., Woroch, B., \& Hirshman, E. (2006). Combined pharmacological and electrophysiological dissociation of familiarity and recollection. Journal of Neuroscience, 26, 1979-1985.

Curran, T., \& Dien, J. (2003). Differentiating amodal familiarity from modality-specific memory processes: An ERP study. Psychophysiology, 40, 979-988.

Curran, T., \& Friedman, W. J. (2004). ERP old/new effects at different retention intervals in recency discrimination tasks. Cognitive Brain Research, 18, 107-120.

Curran, T., Tanaka, J. W., \& Weiskopf, D. M. (2002). An electrophysiological comparison of visual categorization and recognition memory. Cognitive, Affective, $\varepsilon$ Behavioral Neuroscience, 2, 1-18.

Curran, T., Tepe, K., \& Piatt, C. (2006). ERP explorations of dual processes in recognition memory. In A. M. H. Zimmer \& U. Lindenberger (Eds.), Binding in human memory: A neurocognitive approach (pp. 467-492). Oxford, UK Oxford University Press.

Düzel, E., Vargha-Khadem, F., Heinze, H. J., \& Mishkin, M. (2001). Brain activity evidence for recognition without recollection after early hippocampal damage. Proceedings of the National Academv of Sciences. U.S.A. 98, 8101-8106.

Ecker, U. K. H., \& Zimmer, H. D. (2009). ERP evidence for flexible adjustment of retrieval orientation and its influence on familiarity. Iournal of Cognitive Neuroscience, 21, 1907-1919.

Ecker, U. K. H., Zimmer, H. D., \& Groh-Bordin, C. (2007). Color and context: An ERP study on intrinsic and extrinsic feature binding in episodic memory. Memory \& Cognition. 35, 1483-1501.

Feldman, R. S., Meyer, J. S., \& Quenzer, L. F. (1997). Principles of Neuropsychopharmacology. Sunderland, MA: Sinauer.

Finnigan, S., Humphreys, M. S., Dennis, S., \& Geffen, G. (2002). ERP "old/new" effects: Memory strength and decisional factor(s). Neuropsychologia, 40, 2288-2304.

Friedman, D. (2005). ERP studies of recognition memory: Differential effects of familiarity, recollection, and episodic priming. Cognitive Sciences, 1, 81-121.

Friedman, D., \& Johnson, R., Jr. (2000). Event-related potential (ERP) studies of memory encoding and retrieval: A selective review. Microscopv Research and Technique, 51, 6-28.

Groh-Bordin, C., Zimmer, H. D., \& Ecker, U. K. H. (2006). Has the butcher on the bus dyed his hair? When color changes modulate ERP correlates of familiarity and recollection. Neuroimage, 32, 1879-1890.

Hirshman, E., Fisher, J., Henthorn, T., Arndt, J., \& Passannante, A. (2002). Midazolam amnesia and dual-process models of the word-frequency mirror effect. Journal of Memory and Lanquage, 47, 499-516.

Hirshman, E., Fisher, J., Henthorn, T., Arndt, J., \& Passannante, A. (2003). Midazolam amnesia and retrieval from semantic memory: Developing methods to test theories of implicit memory. Brain and Cognition, 53, 427-432.

Hirshman, E., Passannante, A., \& Arndt, J. (2001). Midazolam amnesia and conceptual processing in implicit memory. Lournal of Experimental Psychology: General, 130, 453-465. Kobayashi, S., Fujito, Y., Matsuyama, K., \& Aoki, M. (2004). Differential effects of midazolam on inhibitory postsynaptic currents in CA1 pyramidal cells and dentate gyrus granule cells of rat hippocampal slices. Brain Research, 1003, 176-182.

Kobayashi, S., Fujito, Y., Matsuyama, K., \& Aoki, M. (2005). Comparison of midazolam effects on inhibitory postsynaptic currents in hippocampal CA3 with those in CA1. NeuroReport, 16, 1003-1007.

McCarthy, G., \& Wood, C. C. (1985). Scalp distributions of event-related potentials: An ambiguity associated with analysis of variance models. Electroencephalography and Clinical Neurophysiology, 62, 203-208.

Mecklinger, A. (2000). Interfacing mind and brain: A neurocognitive model of recognition memory. Psychopbysiology, 37, 565-582.

Montaldi, D., \& Mayes, A. R. (2010). The role of recollection and familiarity in the functional differentiation of the medial temporal lobes. Hippocampus, 20, 1291-1314.

Murnane, K., \& Bayen, U. J. (1996). An evaluation of empirical measures of source identification. Memory E Cognition, 24, 417-428.

Norman, K. A. (2010). How hippocampus and cortex contribute to recognition memory: Revisiting the complementary learning systems model. HibDocampus, 20, 1217-1227.

Nyhus, E., \& Curran, T. (2009). Semantic and perceptual effects on recognition memory: Evidence from ERP. Brain Research, 1283, 102-114.

Otten, L. J., Henson, R. N., \& Rugg, M. D. (2002). State-related and item-related neural correlates of successful memory encoding. Nature Neuroscience, 5, 1339-1344.

Paller, K. A., Voss, J. L., \& Boehm, S. G. (2007). Validating neural correlates of familiarity. Trends in Cognitive Sciences, 11, 243-250.

Park, H., Quinlan, J., Thornton, E., \& Reder, L. M. (2004). The effect of midazolam on visual search: Implications for understanding amnesia. Proceedings of the National Academv of Sciences. U.S.A., 101, 17879-17883.

Polster, M. R., McCarthy, R. A., O'Sullivan, G., Gray, P. A., \& Park, G. R. (1993). Midazolam-induced amnesia: Implications for the implicit/explicit memory distinction. Brain and Cognition, 22, 244-265.

Quamme, J. R., Yonelinas, A. P., \& Norman, K. A. (2007). Effect of unitization on associative recognition in amnesia. Hippocampus, 17, 192-200.

Reder, L. M., Nhouyvanisvong, A., Schunn, C. D., Ayers, M. S., Angstadt, P., \& Hiraki, K. (2000). A mechanistic account of the mirror effect for word frequency: A computational model of remember-know judgments in a continuous recognition paradigm. Journal of Experimental Psychology: Learning. Memorv. E Cognition, 26, 294-320.

Reder, L. M., Oates, J. M., Thornton, E. R., Quinlan, J. J., Kaufer, A., \& Sauer, J. (2006). Drug-induced amnesia hurts recognition, but only for memories that can be unitized. Psychological Science, 17, 562-567.

Reinsel, R. A., Veselis, R. A., Dnistrian, A. M., Feshchenko, V. A., Beattie, B. J., \& Duff, M. R. (2000). Midazolam decreases cerebral blood flow in the left prefrontal cortex in a dose-dependent fashion. International Iournal of Neuropsychopharmacology, 3, 117-127.

Rugg, M. D., Allan, K., \& Birch, C. S. (2000). Electrophysiological evidence for the modulation of retrieval orientation by depth of study processing. Iournal of Cognitive Neuroscience, 12, 664-678.

Rugg, M. D., \& Curran, T. (2007). Event-related potentials and recognition memory. Trends in Cognitive Sciences 11, 251-257.

Rugg, M. D., Mark, R. E., Walla, P., Schloerscheidt, A. M., Birch, C. S., \& Allan, K. (1998). Dissociation of the neural correlates of implicit and explicit memory. Nature, 392, 595-598. 
Schloerscheidt, A. M., \& Rugg, M. D. (2004). The impact of change in stimulus format on the electrophysiological indices of recognition. Neuropsvchologia, 42, 451-466.

Senkfor, A. J., \& Van Petten, C. (1998). Who said what? An event-related potential investigation of source and item memory. Journal of Experimental Psvchologv: Learning. Memory. E Cognition, 24, 1005-1025.

Slotnick, S. D., \& Dodson, C. S. (2005). Support for a continuous (single-process) model of recognition memory and source memory. Memory \& Cognition, 33, 151-170.

Snyder, H. R., Hutchison, N., Nyhus, E., Curran, T., Banich, M. T., O'Reilly, R. C., et al. (2010). Neural inhibition enables selection during language processing. Proceedings of the National Academv of Sciences. U.S.A., 107, 16483-16488.

Speer, N. K., \& Curran, T. (2007). ERP correlates of familiarity and recollection processes in visual associative recognition. Brain Research, 1174, 97-109.

Srinivasan, R., Nunez, P. L., Tucker, D. M., Silberstein, R. B., \& Cadusch, P. J. (1996). Spatial sampling and filtering of EEG with spline laplacians to estimate cortical potentials. Brain Topography, 8, 355-366.

Stenberg, G., Hellman, J., Johansson, M., \& Rosen, I. (2009). Familiarity or conceptual priming: Event-related potentials in name recognition. Journal of Cognitive Neuroscience. 21, 447-460.

Tucker, D. M. (1993). Spatial sampling of head electrical fields: The geodesic sensor net. Electroencephalograpby and Clinical Neurophysiology, 87, 154-163.

Veselis, R. A., Pryor, K. O., Reinsel, R. A., Li, Y., Mehta, M., \& Johnson, R., Jr. (2009). Propofol and midazolam inhibit conscious memory processes very soon after encoding: An event-related potential study of familiarity and recollection in volunteers. Anesthesiology, 110, $295-312$.

Vilberg, K. L., Moosavi, R. F., \& Rugg, M. D. (2006). The relationship between electrophysiological correlates of recollection and amount of information retrieved. Brain Research, 1122, 161-170.
Vilberg, K. L., \& Rugg, M. D. (2007). Dissociation of the neural correlates of recognition memory according to familiarity, recollection, and amount of recollected information. Neuropsychologia, 45, 2216-2225.

Vilberg, K. L., \& Rugg, M. D. (2009). Functional significance of retrieval-related activity in lateral parietal cortex: Evidence from fMRI and ERPs. Human Brain Mapping, 30, 1490-1501.

Voss, J. L., \& Paller, K. A. (2006). Fluent conceptual processing and explicit memory for faces are electrophysiologically distinct. Journal of Neuroscience, 26, 926-933.

Wilding, E. L., \& Rugg, M. D. (1996). An event-related potential study of recognition memory with and without retrieval of source. Brain, 119, 889-905.

Woodruff, C. C., Hayama, H. R., \& Rugg, M. D. (2006). Electrophysiological dissociation of the neural correlates of recollection and familiarity. Brain Research, 1100, $125-135$.

Yonelinas, A. P. (2002). The nature of recollection and familiarity: A review of 30 years of research. Journal of Memory and Language, 46, 441-517.

Yonelinas, A. P., Kroll, N. E., Dobbins, I. G., \& Soltani, M. (1999). Recognition memory for faces: When familiarity supports associative recognition judgments. Psvchonomic Bulletin \& Review, 6, 654-661.

Yonelinas, A. P., Otten, L. J., Shaw, K. N., \& Rugg, M. D. (2005). Separating the brain regions involved in recollection and familiarity in recognition memory. Journal of Neuroscience, 25, 3002-3008.

Yovel, G., \& Paller, K. A. (2004). The neural basis of the butcher-on-the-bus phenomenon: When a face seems familiar but is not remembered. Neuroimage 21, 789-800.

Yu, S. S., \& Rugg, M. D. (2010). Dissociation of the electrophysiological correlates of familiarity strength and item repetition. Brain Research, 1320, 74-84.

Zimmer, H. D., \& Ecker, U. K. (2010). Remembering perceptual features unequally bound in object and episodic tokens: Neural mechanisms and their electrophysiological correlates. Neuroscience and Biobehavioral Reviews, 34, 1066-1079. 